\title{
Conclusion
}

\section{The ethos of cosmopolitan responsibility}

\section{Responding to global injustice}

Individuals and their acts do matter morally; even in the face of large and complex global challenges which make individuals and their acts seem to look small and insignificant. This last chapter combines insights from preceding chapters to conclude the exploration of the role and responsibility of individual agentswith a focus on well-off, ordinary citizens in the countries of the Global North -in the face of global structural injustice. It recapitulates key features of a theory of cosmopolitan responsibility, which can be, in the form of a cosmopolitan ethos, personally endorsed by individuals and thus shape dispositions and behaviour. Such an ethos is based on a sense of belonging to a broader, morally relevant community of all humans as equals. It acknowledges the multiple political, economic, environmental, social, and cultural relations, interdependencies and interconnections that link the local, the regional, the national and the global levels with one another, making all humans morally equal citizens of the world.

My considerations may offer some guidance for individuals reflecting on what they should do concretely, but they will not identify precise tasks or specific duties. Given the size and the pervasiveness of structural injustice and its multiple appearances, such ambition would be misguided. Instead, in this book, I argue more generally that the suitable moral response of individuals to structural injustice should consist in developing and fostering an egalitarian ethos of cosmopolitan responsibility that, in overcoming indifference, permeates an agent's thinking and feeling, informs choices, leads to some action directly tackling injustice but also generates indirect effects on other agents in the community surrounding the agent. Such a cosmopolitan ethos of individuals links cognitive and rational normative analysis, with a socially embedded and emotionally charged feeling of relational equality in the global community, and a disposition to act according to the values of cosmopolitan responsibility.

Importantly, determining individual responsibility in terms of an ethos (instead of identifying concrete duties or tasks) has two main advantages: by avoiding atomistic assessments of single acts, the ethos, first, matches individual attitudes and patterns of behaviour (not single acts) with the distinctive wrong of injustice embedded in structures, and, second, it allows to stress the relational and social components of individual agency. Thus, individual responses are not only to be assessed in terms of their (accumulated) actual and direct ("vertical") effect on addressing need or increasing justice; they also matter with re- 
gard to their ("horizontal") effect on other agents, i.e. as contributions to the development of a collective ethos providing an important basis for collective action and, possibly, for successful institutional reform of unjust structures. This last chapter further spells out these claims.

\section{Four features of global individual responsibility}

My account of cosmopolitan, global individual responsibility is characterised by the following four features: it is inherently personal, pluralist, forward-looking, and pragmatic.

The essential feature of cosmopolitan responsibility is its personal nature. It contends that individuals are bearers not only of basic rights, but also of responsibilities which correspond to those rights. Several ways of linking individual agents to collective harms and instances of structural injustice have been discussed in the preceding chapters. The fundamental reason for establishing responsibility is-on universalist and egalitarian terms-the existence of relations between persons. Persons are understood as needy and vulnerable beings on the one hand, and as capable agents on the other. Furthermore, they are understood as common members of morally relevant communities within which they are connected through personal and structural interactions. ${ }^{249}$ In a global community, individuals morally ought to become self-aware about their role and responsibility not only to avoid harm and to remedy harm already caused, but more generally to respect others and secure equality, also by helping to fight moral wrongs and by promoting and securing the rights and flourishing lives of all. The relevant point here is that individuals are called upon to engage in political action and, ideally, work towards structural solutions-even if effectively changing the structures far exceeds their particular capacities. But the impossibility of changing large-scale problems alone does not free anyone from a personal moral obligation to respond to them. Governmental politics and science alone will not fix the problems under discussion unless a sufficient number of persons acknowledge their urgency, call for change, accept some personal responsibility, make use of their capacities, and undertake efforts to address them in one way or another. People within and outside of institutions have to show personal commitment and demand change. Only then will institutional

249 This explicitly includes also possible connections where there is a moral case to be made for such connections, as well as connections to future generations where the impact of today's decisions will impact on their lives. Cf. chapter two, above, on the ideal of relational equality. 
agents-such as corporations, governments or the international community-ultimately feel compelled to take action.

Thus, cosmopolitan responsibility, although distinctively individualistic, is certainly not atomistic and does not isolate individuals. On the contrary, it is based on the insight that persons are, as individuals, dependent on others; they live, interact, and flourish in exchange with others. It also acknowledges that the personal responsibility of individual agents may best be discharged by coordinating with others in order to collectively create adequate institutions. The fundamental point is that individuals matter also as individuals; their single acts, over which they have control, are relevant for flagging problems, for starting to address them collectively and for promoting structural reforms. Thus, individuals are-in spite of the limited direct impact their acts may have-personally called upon as bearers of responsibility for the larger structures they live in.

The moral relevance of such personal involvement with unjust structures can be explained in numerous ways, making the account of cosmopolitan responsibility inherently pluralist. This is its second characteristic. The preceding chapters discussed different forms of entanglement justifying personal responsibility: persons may bear responsibility for their past or ongoing contributions to injustices, they may have a general moral obligation to minimise harm and maximise the good for all, they may have an obligation to foster and develop their own character in a specific way, and they may be required to respect everyone as moral equals in all interactions, including indirect interactions with those temporally or spatially remote. I contend that all these different normative strategies have genuine moral weight, and one should not be forced to give exclusive preference to only one of them. Quite to the contrary, expanding one's view by acknowledging multiple sources of morality should be seen as an opportunity, not as a burden. Such a broader view not only avoids that one misses important moral dimensions of a problem; it also allows a better appreciation of the richness and complexities of the multiple dimensions of human life; it may also help, if deployed wisely, to mobilise a greater number of moral emotions, thus increasing motivation-in contrast to the somewhat impoverished focus of more narrow moral theories relying on a single, rational criterion alone.

However, pluralism has a price: it often comes along with less clear advice than straightforward adherence to a single principle would, particularly because an 'algorithm' to calculate and weigh the competing morally significant perspectives and considerations is unavailable. I also doubt that it will be possible to come up with such an algorithm, neatly integrating the different perspectives. Yet, the risks attached to the pursuit of unambiguous normative neatness are greater than those attached to living with plurality: The suggestion of clarity where it does not exist invites activity under the illusion of knowledge and im- 
pedes the pursuit of engaging further with the problems at hand instead of pursuing the search for adequate ways of engaging with them. ${ }^{250}$ Thus, a pluralist account of responsibility will invite and welcome contributions and assessments from different normative perspectives and attempt to identify morally adequate responses in light of obligations, consequences, connections, etc. And in many cases, at least, significant convergence between different normative perspectives will appear: the general wrongs of global structural injustice can be acknowledged by deontic, consequentialist, virtue-based, contractualist, and other approaches alike.

A third feature of cosmopolitan responsibility is its temporal dimension: it assigns priority to the present and the future, not to the past; responding personally to a given global challenge here and now means to specify the general intuition that someone should be doing something about a problem by determining what can and should be done by whom. Here, initially all those who can address a significant moral wrong are included as possible bearers of moral responsibility. In this regard, cosmopolitan responsibility is extremely inclusive and 'generous' in assigning such initial, forward-looking responsibility. This is done to limit the possibly negative impact of obsessing about past events and activities and blame-shifting, which can undermine and complicate necessary responses to address a wrong (for example by assigning responsibility only to some while letting others too quickly off the hook).

Assigning priority to the forward-looking perspective, however, is not to be identified with exclusivity: Looking back also matters to some degree, particularly when it comes to distributing burdens among several capable agents in a fair way. Those who have done wrong, caused harms, or through doing so are enjoying particular advantages, bear, and should willingly accept, greater forwardlooking responsibilities in acting to address a wrong. The fact that more powerful, privileged agents are frequently unwilling to acknowledge their harmful contributions and instead prefer to engage in blame-shifting, avoid costly remedial action or argue strategically for equal burden sharing is, of course, lamentable. However, it does not speak against the soundness of the normative judgement that past acts generate special responsibilities. But neither does it free other capable agents from their own, past-independent, forward-looking responsibility to address massive moral wrongs today (even if those bearing special responsibility fail to live up to it).

250 To put it pointedly, as a variation of an important insight by Wittgenstein: An unbalanced diet, where one nourishes one's thinking with only one kind of normative reasons, is the main cause of philosophical disease (cf. Wittgenstein 1953, §593). 
The fourth characteristic of global individual responsibility is its pragmatic nature. By this I mean a combination of three features: epistemic humility, an optimistic belief in the possibility of progress, and practical ambition.

Pluralism, already mentioned above, makes a case not to strive for unambiguousness but instead to use the best available theoretical and practical tools to assess a given challenge and weigh adequate options of response. Acknowledging epistemic limitations-resulting from incomplete factual knowledge on the one hand and selective or narrow perspectives on the other-supports an attitude of modesty in making judgements and in prescribing specific actions. Epistemic modesty then demands a general willingness to hear other opinions, to listen to the voices of all affected, to engage with them on terms of good faith, and to pursue the task of identifying an adequate moral response to a given problem together. Modesty in this regard, however, must not be confounded with a weakened willingness to defend one's judgements: defending one's own, well-considered point of view by explaining it with the help of good arguments that are accessible to others, is an integral ingredient for successfully determining appropriate solutions.

The second pragmatic element is a general yet non-naive optimism, which asserts that progress towards a better future, in which current problems are increasingly being addressed and can eventually be solved, is possible. Taken together with the forward-looking perspective and the call for epistemic modesty, it calls for a wide and inclusive dialogue about what such a better future would entail and what would be necessary to bring it about. It seeks to articulate values and ideas, rights and responsibilities that promote progress by remedying relational inequalities and structural injustice, and by promoting circumstances for flourishing lives for all. And it also remembers past instances of successful progressive change to refute pessimistic or apathy-inducing voices.

Practical ambition, the disposition to transform one's attitudes, value judgements, and one's perception of connectedness in a morally relevant community into concrete acts, is a third element of the pragmatic nature of cosmopolitan responsibility. It deserves particular attention and thus will be taken up in the following section.

These four features-personal, pluralist, forward-looking, and pragmaticcharacterise the normative outlook of cosmopolitan responsibility in general terms. Now, the task ahead is for each agent to respond personally by considering his or her role in the problematic structures at hand and by analysing and improving behaviour. 


\section{The cosmopolitan ethos}

The primary philosophical ambition of this book was to defend the normative outlook of cosmopolitan responsibility by exploring norms, values, and ideals that shape our understanding of the roles and responsibilities of individual agents in a globalised, interconnected world. These normative considerations yield practical relevance when they shape the ethos of an agent; where the ethos is understood as an intra-personal 'institution' integrating normative values and considerations in one's motivational setup, influencing one's dispositions to act, and thus leading to tangible individual responses to global structural injustice. Importantly, such an ethos can spread beyond what an individual feels, thinks, says and does; it can inform others and invite dispositional and behavioural change in them, too.

To make sense of this claim and to explain the link between the theoretical, social and behavioural dimensions of moral action, the notion of an ethos required clarification. ${ }^{251}$ An ethos was understood as a set of values, norms or principles that, held explicitly or implicitly, informs practice. It is an internalised endorsement of values underlying a person's or a group's way of perceiving and categorising different states of affairs, shaping both the conscious and unconscious responses to specific situations or stimuli, and determining the range of options and actions perceived as appropriate to choose from when confronting an issue. In other words, an ethos shapes people's ways of feeling and thinking, and their dispositions to communicate and to act about something. In this sense, an ethos is pervasive: it is embedded in the basic setup or character of a person and motivates corresponding action. ${ }^{252}$ Importantly, however, this setup is neither static nor immune to change. Instead, it can be shaped and developed through such different practices as critical reflection and argumentation, seeing and copying what others do, and, not least, through education, both through factual information and emotional storytelling. ${ }^{253}$ Inferences about the ethos of a

251 Cf. Wolff $(1998,105)$, and above, chapter one, section 5.3.

252 Cohen called it "a structure of response lodged in the motivations that inform everyday life" (Cohen 2000, 128).

253 The United Nations's Sustainable Development Goals mention in target 4.7 the need for global citizenship education as a way to promote sustainable development also through increasing knowledge and inviting individual behavioural change. UNESCO's guiding document on topics and learning objectives of global citizenship education directly tackles this target, rightly pointing out the importance of the cognitive, the social, and the behavioural dimensions (UNESCO 2015). The practical importance of the "sentimental" aspects of promoting cosmopolitanism is highlighted also by Rorty (1998), Long (2009), and Woods (2012). 
person are possible based on what someone says and does; such visible expressions of an ethos provide information and communicate normative commitments to others in the surrounding social community of an agent, thus generating "horizontal" effects on other agents. In this regard, the personal, i.e. one's internal commitments shaping observable behaviour, becomes inevitably public and political within a shared social space.

This description indicates how the ethos as an intra-personal 'institution' provides a possible link between the cognitive-rational side of persons, their often emotionally charged relations and social interactions, and their dispositional-behavioural setup, which shapes their actions. The point is that the cognitive dimension, the socio-emotional dimension, and the practical dimension of human lives are not separated from one another, but are closely connected and mutually influence each other. In order to promote lasting dispositional and behavioural change, all these dimensions need to be considered. The focus of philosophical ethics to engage first and foremost with the cognitive rational analysis of normative claims thus is but one part of the full story. Understanding how normativity can actually shape behaviour, and making good use of the psychological dynamics and mechanisms that help people shape and change their behaviour and embrace new, morally superior habits and conduct (both in individuals and in collectives) goes beyond philosophical analysis alone. Here, the analysis of the cognitive dimension should be enriched by paying attention to the social-emotional and dispositional-behavioural dimensions, as well. ${ }^{254}$ The remaining pages of this book provide further thoughts on the ethos of persons in an attempt to do just this.

254 With this practical goal in mind, much can be learned from empirical studies in the social sciences and in social psychology about the creation and functioning of norms and the mechanisms of norm diffusion and effective norm change in individuals and social groups (cf. e.g. Elster 1991, Bicchieri 2016). For psychological research that can support the present philosophical project, cf. e.g. Buchan et al. (2011) and de Rivera and Carson (2015). The connection to the proposed focus on the "ethos" of persons and groups should be obvious, since social norms are understood as "socially shared and enforced attitudes specifying what to do and what not to do in a given situation" and norms "do not just specify what people ought and ought not to do; they also specify what people actually do, what they think, and how they feel." (Prentice 2012, 23-24). Humans are social beings very much influenced in their own dispositions to think, feel and act by what they think about what others think, how others feel and act.-In this philosophical study I am unable to give full justice to research in social sciences and psychology but others have started to take up the findings in these disciplines to discuss effective ways to communicate cosmopolitan norms so that they influence human behaviour (e.g. Brock and Atkinson 2008, Goodman, Jinks et al. 2012, Cameron 2017). 
But why bother with apparently idle and idealistic talk about changing an ethos, when any reasonable person has to acknowledge that humans are persistently driven by selfish interests, neglect the legitimate and basic claims of others, and even knowingly accept the suffering and death of others and the deterioration of the environment simply to enjoy some, often rather trivial advantages? Why not give up hope altogether, in light of all the past, obviously unsuccessful attempts to realise a just world, and a current political climate in which populist, nationalist, isolationist and supremacist discourse seems to grow-employing denial, confusion, and blame-shifting strategies to legitimise the continuation of selfish practices and inaction-at the expense of internationalist and cosmopolitan discourse?

All this has to be seen and acknowledged. And yet: I do not see why it should be impossible that people and policies change, as they have done so often already in the past. ${ }^{255}$ Things can change for better or for worse, but change they can. The sheer possibility of change-of both progress and deteriorationthus calls upon all morally sensible people to contribute their share; even if it is only small, and even if it faces a quite hostile political climate shaped by denial, parochialism, ineffectiveness, and outright passivity. To counter this, the very privileged are clearly called upon, as are those who occupy positions of influence. Activists leading the fight for change are urgently needed, too. But also ordinary citizens, if they are privileged enough to be able to inform themselves and engage in some form of action, are called upon to use their abilities. Apathy and inaction are simply not morally acceptable options in the face of the massive wrongs that shape our current world, and the impending threat that things will only get worse. Which, then, are the essential features of a cosmopolitan ethos?

Acknowledging problematic connections and relations. The original problem of structural injustice is, as we have seen above, that much of the current global inequalities and injustices are frequently not even perceived as being of concern to the privileged individuals living in the countries of the Global North. The manufacturing conditions of consumer products are at best briefly regretted but ultimately ignored; the pollution resulting from mobility is occasionally lamented but does not lead to sufficient behavioural change; the wealth and security within countries of the Global North is considered as unproblematic and generally

255 The standard examples of change for the better include the abolition of slavery in many parts of the world, increasing equality between women and men, the decriminalisation of consensual sexual relations that were formerly labeled as deviant. Obviously, further steps still need to be made in all these fields, but this must not obscure the fact that significant achievements have been already made and that progressive change, that replaces old expectations of normalcy, is possible. 
justified, so that others are either fully ignored or seen as undeserving or not entitled to equal standards of security and well-being. All this leads to a situation in which the suffering and deprivation of others are conveniently kept hidden from sight, often with the help of walls, fences and force. This set of dispositions is widely shared and can itself also be characterised as an ethos, although as one opposed to its cosmopolitan and egalitarian antithesis: an ethos endorsing a parochial view that insufficiently acknowledges, or even denies, both the existing connections and the equal moral standing of all.

The alternative cosmopolitan ethos acknowledges the existence of transnational, cosmopolitan relations and connections of all within a global community. These connections have both a factual basis, e.g. in the form of economic interactions, or the transnational effects of the global climate shaping our globalised and interconnected world, but also an ideal basis, i.e. the idea of a morally relevant community of morally equal global citizens who are willing to put themselves in the shoes of others and foster concern for how the lives of others go. In this scenario, indifference and inaction towards the fate of other fellow humans in need are understood as denial and rejection. From the perspective of a cosmopolitan ethos it is imperative to replace this indifference with explicit acknowledgment of a morally relevant relationship. The task ahead consists in seeking to develop that pre-existing, more parochial ethos with its insufficient acknowledgement of the equal moral status and relevance of all into a cosmopolitan ethos. This will move concern for the globally disadvantaged from the periphery more to the centre of people's concern, calling also for corresponding individual action.

Individual action in social context. Yet, ending the problems of global structural injustice through individual agency alone will be impossible, as anyone considering acting to address such large-scale challenges will immediately become aware of. Furthermore, when considering the number of important, morally urgent tasks, agents will realise, at least under current circumstances, the difficulties, even the impossibility of always acting in line with the pluralist demands of moral cosmopolitanism that assigns equal moral value to everyone and stipulates morally relevant relations between all within the mutual sphere of influence. So many of our everyday acts are morally tainted, as a critical reflection on consumer decisions, the everyday needs for mobility, or the preferential treatment extended to those near and dear to oneself, clearly indicate. Thus, seeking moral perfection is not a plausible goal. The task for individual agents hence cannot consist in obsessing about keeping one's hands perfectly clean or always attempting to do everything perfectly right; instead, it consists in making well-considered choices regarding how much one is willing to do, and about how many costs one is willing to accept to promote the good. It forces agents to 
place themselves on a spectrum of being more part of the problem or more part of the solution. Individual agents can always choose from numerous options, forcing upon themselves an inevitable decision about whether they want to start acting and how far they want to go. But importantly, they can start and improve, right away.

From the perspective of cosmopolitan responsibility, the sheer ability to choose from these diverse options-including the morally problematic option to remain inactive-is in itself a vivid indicator of privilege. Such undeserved privilege comes along with additional powers that often remain unappreciated and even undermine the motivation to expand the circle of concern for others. Awareness of this privilege, however, points out how relatively easy it would be, under conditions of security and abundance, to change behaviour and to ask for and promote political reforms. While the globally disadvantaged, if they have a chance to be heard at all, often have to accept immense risks when speaking up against exploitative employers, multinational companies, or oppressive regimes, the possible costs for endorsing a more egalitarian and cosmopolitan mindset as a globally privileged person are rather small, making it, I contend, a matter of simple decency to develop the egalitarian ethos and see to it that it translates into some concrete action.

The available options for action that individual agents may choose to realise in accordance with the normative outlook of cosmopolitan responsibility are numerous. The problems calling for cosmopolitan concern abound, as do the possibilities to address them, also from the perspective of individual agents. All responses are steps towards reducing the "passive injustice" that consists in inaction. ${ }^{256}$ Options range from informing oneself and others about the problems to raise awareness; talking about them and taking a stance, both in private settings, such as the family, and in more public settings, for example at work; keeping ideas about alternatives to the current problematic situation ready, developing them further so that they are available at times when they could become effective; practically, agents can aspire to reduce their unintentional involvement in causing harm or upholding injustice; further options include the possibility of donating time or money to organisations actively addressing need and injustice, or even working in or for such organisations; to self-limit one's own wealth and use of resources and to make ethically considered consumer decisions; and, of course, for those who see this as a good fit for themselves, political, civic or activist engagement-e.g. in the form of inspiring creative, provocative or disrup-

256 The notion of "passive injustice" has been coined by Shklar, albeit in a narrower sense than I use it here (Shklar 1990, 6). 
tive, thought stimulating, symbolic action-is also an important option available to most citizens living in the affluent liberal democracies of the Global North (that may even invite and support such engagement). ${ }^{257}$ Taking the perspective of cosmopolitan responsibility with its commitment to relational equality will encourage privileged citizens of the world to consider such actions and to engage in as many of them as reasonably possible. I do not offer a concrete minimal or a maximal set of obligations, because, in any case, it is impossible to avoid some degree of moral failure or to reach moral perfection (cf. chapter six). Because of the morally disastrous circumstances of structural injustice the privileged cannot hope to be doing enough; moral awareness and sincerity will not cease to demand more as long as others, living under conditions of preventable misery, can be helped. But it seems clear that, from the perspective of cosmopolitan responsibility, most, if not nearly all of the privileged citizens should move these concerns for structural injustice more to the centre of their own and the public attention and should be doing more to address them than they currently do.

Challenges to taking cosmopolitan action. Sure, endorsing a cosmopolitan ethos and displaying the corresponding behaviour frequently causes some friction with and irritation among those who do otherwise; such tensions increase with the consistency and costliness of the non-standard behaviour. Different kinds of counter-arguments and self-defense mechanisms are then advanced in order to justify continuing with the problematic, established patterns of behaviour. Blaming moral agents as naive "do-gooders" is one prominent strategy. ${ }^{258}$ But-as long as no severe harassment, violence or abuse takes placethe costs incurred for moral decency are of rather limited weight compared to the costs suffered by those whose rights and plights are ignored, and who are often unable to make their voices heard, be it because they are struggling for survival or because they are dominated, threatened or silenced. Here, a general change in norms and in what is considered acceptable behaviour is needed; and there is no reason why such change should not, eventually, be possibleas many instances of progressive change in the past have shown. Each instance of such change started with some people moving first, others contributing, and

257 Further thought on the special role of academics can be found e. g. in Caney (2012) and Horton (2014); on civil disobedience that combines symbolic with confrontational ambition cf. e.g. Celikates (2016) and Delmas (2018). For an exemplary discussion of individual responsibility in the context of refugee and migrant integration, cf. the contributions to Kehoe/Alisic/Heilinger (2019), among them Grahle, Heilinger, and Phipps.

258 Attacking "do-gooders" is discussed e.g. in Sezgin (2017). For online attacks against academics speaking up for justice cf. e.g. Branford et al. (2019). 
in doing so setting new trends, while initially also accepting criticism for their unusual behaviour. ${ }^{259}$

But how far will a cosmopolitan ethos actually shape agency? Can one ever do enough? Will agents, with the right ethos, have to dedicate their entire lives to addressing global structural injustices or other moral wrongs? Is it still permitted to assign (some) preference to those particularly near and dear to oneself? Clearly, doing more in order to promote the good is, from the moral point of view, always better than doing less, and engaged and committed activism is urgently required. But human lives have many facets and earning one's living, raising one's children, and taking care of oneself also matter and command attention. These circumstances may even explain (but not justify) why many people actually do not do more to address global injustice and thus fail to live up to cosmopolitan demands. However, moral concern in thinking about the problems at hand should not primarily be directed to the fate of the privileged individual agents and their concern about the ability to reach moral perfection (cf. chapter six). Instead, it should be primarily directed to the need of the disadvantaged and to the conditions of injustice. From this starting point it has to be asked whether and how it is possible to contribute to changing the circumstances that so negatively impact on so many people's lives.

It is one of the distressing truths of this world, that each act has opportunity costs. Thus, even apparently innocent acts, especially under circumstances in which an alternative to reduce injustice or secure rights would be available, have a price-a price born by those whose plight remains unheard, who are not helped. However, it is not my ambition to suggest that all should radically change their lives by suddenly ignore all special relationships and responsibilities and become concerned in a perfectly impartial way exclusively about the global problems at the centre of this book. Few would be impressed by such an argument, no one would follow it.

The importance of some people dedicating their lives primarily, even exclusively, to fighting injustice is undeniable. Moral progress and social change need such agents willing to incur high costs, take risks and expose themselves. But cosmopolitan responsibility is-on its more modest, realistic and practical side -an ideal accessible and relevant for many more people: everyone morally ought to contribute to the task of increasing justice by integrating awareness of the existing injustice in their everyday decisions and acts. And this demand

259 On the role of individual "trendsetters" in norm change, cf. Bicchieri (2016, ch. 5), on "norm entrepreneurs" who can start "norm bandwagons" and trigger "norm cascades", cf. Elster (1997, 35 -37). In the context of climate change, Jamieson has made a case for the importance of developing virtues and of leading by example in responding to climate change (Jamieson 2005). 
can be met even if one does not, or does only on occasion, take up the role of a committed activist.

The focus of the present book was, as indicated in the beginning, on 'ordinary' citizens. Their role must not be underestimated. It is crucial for promoting and securing global justice and equality, because some general concern for the problems at hand and a general commitment to addressing them needs to permeate society. To realise this goal, the outstanding acts of the few are important, but the commitment of anyone objecting to the current state of affairs will be imperative, too. And contributing to establishing a broad and sound basis for progress in addressing existing injustices is very well compatible with exercising other roles responsibly: It is possible to be a baker, teacher, bus-driver, parent, etc. and to display an egalitarian ethos that tangibly translates into feeling concern, acknowledging responsibility, talking about connections, and, of course, also taking action-as a political being and engaged citizen, as a consumer, as a friend-in ways that take background injustices into account and contribute to addressing them.

Individual impact. Focussing on the ethos of people and groups of people, and not prescribing specific acts, is particularly promising in the context of global structural injustice, where the moral wrong in question is itself not constituted by single instances of morally flawed action, but is pervasively embedded in the (global) social structures and the standard patterns of interaction and behaviour. Climate change, economic unfairness and world poverty are important examples. Here, a single instance of a good action (even if it is very much effective in saving or significantly improving the life of one or the lives of a few people) is insufficient to address the general, structural wrong-in the same way as single problematic acts are not at the origin of the structural wrong in question. Correspondingly, only a change in those structures and patterns of action and interaction, both in individual and in institutional agents, can adequately address such wrongs. And while ordinary individuals cannot directly change structures and institutions, they have an impact on the level of other individuals that constitute and shape them.

Thus, individual action is in no way futile. Two factors particularly increase the impact of individual behaviour. First, if people do not only act once in a certain way but change their dispositions, patterns and habits of action, this repetition will add up and increase the impact of their acts. Hence, the narrow scope, often dominant in ethics, to assess single acts must be widened so that individual behaviour over longer time-spans, potentially for the duration of an entire life, is taken into account. In this way, cumulative effects can be considered as well. On this account, the effects of individuals can really make a difference; even if unmeasurable on a global scale, they can make a significant difference 
for some. Second, as social beings, humans are attentive to the behaviour of others and perceive norm deviation-also new, morally improved behaviour-as an irritation that challenges the established patterns of behaviour. Such irritation, the moment in which standard behaviour becomes problematic, often is the beginning of inquiry (cf. above, chapter three, section three). Thus, every instance of it should be seen as a welcome trigger to start a collective reconsideration of current and insufficiently questioned practices, guided by the ambition to realise relational equality for all. Those taking action towards this goal thus influence other possible agents-through irritation, through information-and can contribute to establishing new, better standards of thinking and acting.

Of course, the call for accepting global connectedness and furthering cosmopolitan concern and responsibility seems to run against much of the current of our time. Maybe, in hindsight, the COP21 United Nations Climate Change Conference in 2015, which led to the Paris Agreement, will be considered as a peak of a globally interconnected human civilisation and of the international cooperation that began increasing after World War II. Six months later, the British voted for "Brexit"; five months later, Donald Trump was elected president of the USA; populist movements in many countries further gained in strength and, at the time of writing, an end to the rise of parochialism and nationalism does not appear to be in sight. In the light of such powerful current political developments and the spread of what could be called an anti-cosmopolitan ethos, calling for relational equality and cosmopolitan responsibility might appear irritatingly untimely and naively optimistic. Yet, the isolation of individuals and communities is not a viable option. No matter whether we like it or not, today we live in a global sphere of mutual influence, and mutual effects are inevitable; the circumstances of cosmopolitanism are an undeniable fact of our time. We are all in this together. This makes it imperative to develop and foster a rationally justified, emotionally felt, socially embedded and action-guiding cosmopolitan ethos of responsibility, no matter how bad the current odds stand. Every individual is thus faced with the existential choice of being part of the problem or part of the solution-acknowledging equality, connectedness, and responsibility in what one does.

\section{Citizens of the world}

It is time to conclude this book. I set out to analyse the dazzling link between large and complex global structural injustices on the one hand and the smallest unit of agency, the individual person on the other. I inquired into the moral roles and responsibilities of individuals, particularly the relatively well-off ordinary citizens in the affluent countries of the Global North. With my focus on individ- 
ual behaviour, I have taken a bottom-up perspective to complement the important ongoing debates about global institutional (in-) justice by providing the outlines of a global political ethics, specifying individual responsibility through an account of a cosmopolitan ethos. This was defended in full awareness of the limited impact most of our individual actions will have. Yet, societies and institutions are set up by people, and they depend on individuals to shape them. Cosmopolitan reforms will take place only if they are demanded, and change thus can start where ultimate moral agency lies: with the individual agent demanding it and working towards it.

Based on the proposition defended above that individual moral agents matter-simultaneously as beings with legitimate needs and claims on the one hand, and as agents able to act according to normative convictions on the other-I have sought to develop the core elements of a cosmopolitan ethos that can and should inform how people respond to the challenge of living together in a global community. This ethos and its normative ideas yield practical relevance by being able to shape everyday habits and actions of individuals and groups. In particular, equality is neither a remote or theoretical ideal, nor a static state of affairs. On a relational account, equality is a practice. It is something agents can do.

It is my sense that the experience and acknowledgment of the joint co-existence and mutual influence of all on this planet can and ultimately must become transformative. The global sphere of citizenship, and a global civil society, increasingly materialises from rather abstract ideas into a felt reality. The random and arbitrary contingencies that assign everyone a place in the world will then, particularly for all those enjoying privileges and relative advantages, be re-envisioned as merely the position from which they contribute to the perennial moral project of acting responsibly as citizens of the world. 